\title{
Poly(ADP-ribosyl)ation in mammalian ageing
}

\author{
Sascha Beneke and Alexander Bürkle* \\ Molecular Toxicology Group, Department of Biology, University of Konstanz, D-78457 Konstanz, Germany
}

\begin{abstract}
Poly(ADP-ribose) polymerases (PARPs) catalyze the post-translational modification of proteins with poly(ADP-ribose). Two PARP isoforms, PARP-1 and PARP-2, display catalytic activity by contact with DNA-strand breaks and are involved in DNA baseexcision repair and other repair pathways. A body of correlative data suggests a link between DNA damage-induced poly(ADP-ribosyl)ation and mammalian longevity. Recent research on PARPs and poly(ADP-ribose) yielded several candidate mechanisms through which poly(ADP-ribosyl)ation might act as a factor that limits the rate of ageing.
\end{abstract}

\section{INTRODUCTION}

Poly(ADP-ribose) (PAR), the reaction product of the large family of poly(ADP-ribose) polymerases (PARPs), has been discovered in the 1960s (1). Since then, this molecule and its producers have made an astounding career from an obscure side reaction of cellular DNA damage to the 'Swiss army knife' for the maintenance of genomic stability. The areas of involvement of PARPs range from the modulation of DNA repair and the regulation of chromatin structure $(2,3)$ to transcriptional regulation (4-8), mitotic spindle organization (9-12), telomere maintenance (13-16), regulation of trafficking (17-19), involvement in multi-drug resistance (20), to cell death activation $(21,22)$. Understanding the underlying mechanisms of PARP-mediated regulation is a prerequisite for interpretation of the results linking PARP activity to mammalian ageing. In this review, we are focussing on the aspects related with ageing processes, including cancer.

\section{Ageing and the connection to PARP \\ Ageing is a multi-factorial process and has been defined as time-dependent general decline in physiological function of an organism, associated with a progressively increasing risk of morbidity and mortality. It is apparent that during ageing different organs are losing their functional reserve and plasticity and become less able to fulfil their physiological function, especially under conditions of}

stress. Molecular hallmarks are (i) changes in extracellular components (i.e. collagen-matrix, deposits in the vascular system), (ii) changes in cellular metabolism (i.e. DNA repair, protein surveillance) as well as (iii) cellular functionality (senescence and cell death). To maintain their ability to act and respond in an appropriate way, cells have to protect their genomic information from the constant attack of internal and external damaging agents. DNA repair and DNA damage signalling pathways are major factors determining the cellular fate. PARPs have been shown to be a central hinge in maintaining genomic stability. PARP activity is important for repair of DNA single- and double-strand breaks, facilitates mitosis by interaction of PAR with the spindle apparatus, is involved in the decision of life and death after genotoxic insults, helps regulating the integrity of the chromosomal ends, and is a crucial mediator in inflammatory responses, thus covering all three points mentioned above. Disturbances in any of these pathways may lead to senescence or cell death, thus decreasing the functionality of the harbouring organ. Another detrimental outcome may be cancer initiation. How are PARPs able to integrate so many tasks? The following sections will discuss this point by point.

\section{PARP and cell death}

PARPs use NAD ${ }^{+}$as a substrate from which they cleave off nicotinamide and form, via repeated reaction cycles, a polymer of ADP-ribose units, which can be branched $(23,24)$ (Figure 1). Interestingly the main target proteins ('acceptors') are PARPs themselves, which is referred to as PARP automodification. Cellular PAR formation is dramatically stimulated after exposure to DNA-damaging agents that induce single- or double-strand breaks in DNA (25). This kind of induced PAR formation depends on the activation of two abundantly expressed members of the PARP family, i.e. PARP-1 and PARP-2, with PARP-1 activity accounting for $\sim 90 \%$ of the polymer produced under these conditions (26). Under conditions of genotoxic exposure poly(ADP-ribose) undergoes a rapid turnover, since, in parallel with the synthesis of polymer, its enzymatic catabolism is highly active. This is catalyzed by poly(ADP-ribose) glycohydrolase (PARG) and leads to the formation of free monomeric ADP-ribose. The latter compound can be recycled for $\mathrm{NAD}^{+}$synthesis, but this

\footnotetext{
*To whom correspondence should be addressed. Tel: +49 7531 884035; Fax: +49 7531 884033; Email: alexander.buerkle@uni konstanz.de
} 


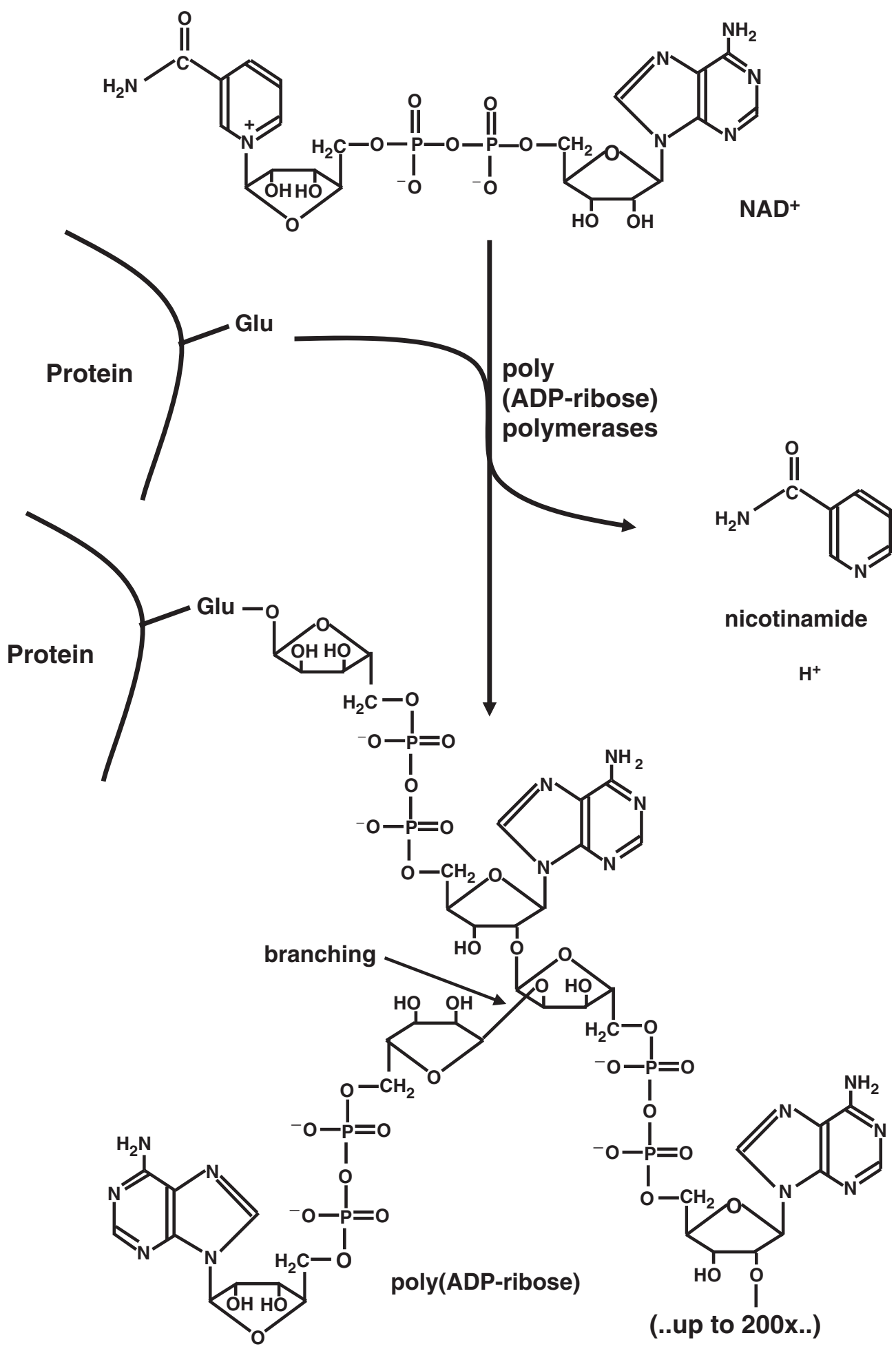

Figure 1. Synthesis and structure of poly(ADP ribose). $\beta \mathrm{NAD}^{+}$is used as a substrate by poly(ADP ribose) polymerases. Nicotinamide is released and the residual ADP ribose moieties are joined in an $\alpha$ glycosidic manner, covalently attached to a glutamate or aspartate of the acceptor protein. Chain lengths can be up to 200 residues with the possibility of branching every 50 units.

requires large amounts of ATP, and as a result cellular $\mathrm{NAD}^{+}$levels drop significantly in this process.

For a long time, the response to genotoxic insults was thought to be the only primary action of PARP(s), and indeed a large body of data has accumulated showing that, perhaps surprisingly, both PARP overactivation $(21,27)$ and the inhibition of the moderate, 'physiological' PARP activity induced by low numbers of DNA strand breaks 


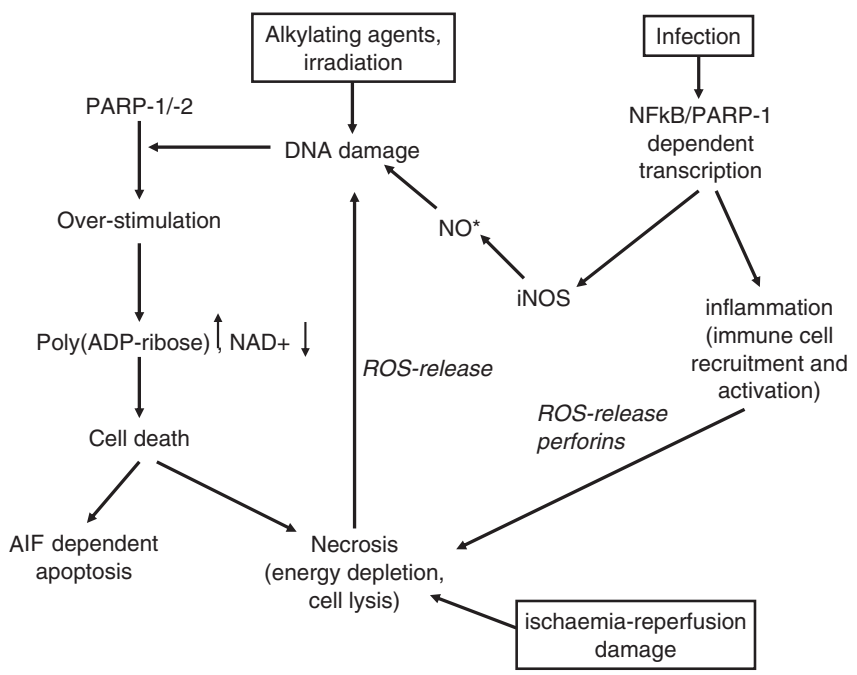

Figure 2. Cell death induced by the activity of poly(ADP ribose) polymerases. DNA damage induced by various stimuli triggers the formation of PAR by PARP 1/2. Depending on the cell type and the energy capacity, PAR can either directly induce cell death by AIF release or by energy depletion. In this process, necrotic cells release themselves ROS, accelerating the effect. Ischaemia reperfusion damage acts on the same line. PARP 1 also interacts with $\mathrm{NF \kappa B}$ in inflammation processes, which induce cellular NO formation by inducible NO synthase (iNOS) and accumulation of reactive products. Also, cytokine production and subsequent immune cell stimulation is under control of $\mathrm{NF \kappa B}$, leading to target cell lysis with release of pro inflammatory cytokines and death of surrounding cells.

increase cell death. Interestingly, PARP inhibition potentiates the incidence of genomic instability induced by genotoxic exposure (28-30) while PARP-1 overexpression has a suppressive effect $(31,32)$. An obvious explanation could be that inhibited PARP-1 and PARP-2 cannot contribute to repair pathways anymore or have even negative functions. Therefore, unrepaired lesions either are substrates for other repair processes like homologous recombination (HR) or lead to cell death. In summary, inactive PARP leads to massive cell death due to unrepaired DNA damages and subsequent apoptosis, with escaping cells being genetically altered. On the other hand, hyperactive PARP restricts genomic instability, but kills the cell by energy failure; survivors are not or only moderately altered genetically.

Cell death by active PARP is mediated by at least two separate mechanisms. First, massive activation of PARP by excess DNA damage leads to a drop in cellular NAD ${ }^{+}$ levels. In order to regenerate this very important cellular energy carrier, ATP has to be consumed in large amounts and cells die from necrosis. On the other hand, PARP activity can induce caspase-independent apoptosis (Figure 2). Recent data suggest that PAR releases apoptosis-inducing factor (AIF) from the inter-membrane space of mitochondria $(22,33,34)$. AIF then translocates into the nucleus and induces high-molecular weight DNA fragmentation (35). Which mechanism of cell death is used probably depends on the cellular system and the stimulus applied. During classical apoptosis there is an initial burst of PAR production $(36,37)$ followed by cleavage of
PARP-1 and PARP-2, probably in order to preserve energy for the apoptosis execution programme by stopping PARP activation and thus $\mathrm{NAD}^{+}$consumption. Regardless of the precise mechanism by which cell death occurs, this phenomenon has an important impact in pathophysiological settings (Figure 2). In models of ischaemia-reperfusion damage, PARP inhibitors have been used to minimize the affected area $(38,39)$. The tissue damage accompanied by ischaemia leads to massive cell death and release of reactive oxygen species (ROS), which damage surrounding cells, activate PARP-1/-2 and induce further cell death, thus spreading the necrotic area. Interfering with this vicious cycle by PARP inhibition obviously has beneficial effects. Additionally, PARP-1 is not only involved in the cellular reaction to ROS, but also in ROS production (see next section).

\section{PARP-1 and transcription}

In 1983, Roeder and colleagues identified PARP-1 as a transcription factor (TFII-C) relevant for regulation of transcriptional initiation (4). Subsequently, PARP-1 has been shown to interact with and modify several classical transcription factors $(5,40,41)$. Most strikingly, Parpl (formerly called $A D P R T$ ) knockout mice are protected from septic shock $(42,43)$ and some pathological effects in various inflammatory diseases (see above). This depends partially on the requirement of PARP-1 for NFKBcoupled transactivation. $\mathrm{NF \kappa B}$ is the major transcriptional regulator in the immune system. Failure to activate it dampens the immune response, which may be advantageous in settings of deleterious over-stimulation of the immune system. For example, the gene encoding inducible nitric oxide synthase is a prominent target of $\mathrm{NF \kappa B}$ transactivation. The product of this enzyme, nitric oxide, and downstream reaction products such as peroxynitrite are potent DNA-damaging agents, which lead to PARP$1 /-2$ stimulation. PARPs consume $\mathrm{NAD}^{+}$during this process with potentially lethal outcome (see above). PARP inhibition has been shown to rescue cells and tissues in different experimentally induced pathological conditions such as colitis $(44,45)$, MPTP-induced Parkinson syndrome (46), ischaemia-reperfusion damage (47-50) and type-I diabetes (51-53). These disease-associated features could be referred to as the ageing-promoting dark backyard' of PARPs (Figure 2). On the other hand, fully functional NFKB is indispensable for normal activation of the immune response. Ageing of the immune system leads to a less pronounced defensive response to infectious agents and therefore to increased mortality. This important branch of involvement of PARPs in ageing needs to be analysed more closely than it has been in the past.

\section{PARP and DNA repair}

The best understood function of PARP-1 and PARP-2 is regulation of the base excision repair pathway (BER), especially the decision between short-patch and longpatch repair. DNA-base excision repair occurs in a 'passing the baton' fashion $(54,55)$. After recognition and excision of the damaged base by type II or type I base glycosylases, the sugar-phosphate backbone of DNA is 
cleaved on the $5^{\prime}$ side either by the same or an additional enzyme, respectively. The $5^{\prime}$ dRPase activity of DNA polymerase $\beta$ cuts out the residual sugar moiety and fills in the gap in a one-nucleotide synthesis step, followed by sealing the nicked DNA by DNA-ligase III (short-patch repair). Blocked terminal ribose residues can lead to a switch to long-patch repair either by stimulating the strand-replacement synthesis activity of polymerase $\beta$ or by alternative usage of the processive DNA polymerase $\delta$. The resulting DNA overhang is cleaved by flap endonuclease $1(\mathrm{FEN}-1)$ and the nicked DNA is ligated. In-vitro data point to a necessity of PARP-1 for the activation of the long patch pathway (56-58). If direct repair by DNA polymerase $\beta$ is blocked, PARP-1 helps out by switching to the alternative route by poly(ADP-ribosyl)ation and attracting auxiliary proteins. Furthermore, PARP-1 stimulates the strand-displacement synthesis activity of DNA polymerase $\beta$ with the help of FEN-1 (59). In vivo, the chromatin relaxing activity of PAR may aid in this process and is therefore likely to be involved in short-patch BER also. Indeed, even slightly poly(ADP-ribosyl)ated PARP-1 is able to recruit the scaffold protein XRCC1 (60-62), which interacts with DNA polymerase $\beta$ as well as with DNA ligase III. Interfering with poly(ADP-ribosyl)ation by pharmacological inhibition, dominant negative competition or genetic knockout leads to genomic instability, as mentioned above. If single-strand breaks arising during the repair process are not ligated, the next round of replication may produce a double-strand break, which is potentially lethal (63). Therefore, cells activate the doublestrand break repair machinery, i.e. either homologous recombination ( $\mathrm{HR}$, during $\mathrm{S} / \mathrm{G} 2$ phase of the cell cycle), or non-homologous end-joining (NHEJ). Surprisingly, PARP-1 and PAR also interact with DNA-dependent protein kinase (DNA-PK), a heterotrimeric enzyme complex belonging to the family of phosphatidylinositol3-kinase-like kinases (PIKK) involved in DNA damage signalling. The catalytic subunit DNA-PK $\mathrm{Cs}_{\mathrm{cs}}$ and also the $\mathrm{Ku} 70$ autoantigen are in vitro targets for covalent ADPribosylation (and also for non-covalent PAR binding), and vice versa. PARP-1 is a substrate for phosphorylation by DNA-PK (64-66) (Figure 3). The activity of DNA-PK ${ }_{\mathrm{cs}}$ is stimulated by poly(ADP-ribosyl)ation. The rationale for the interaction between these two enzymes is not clear. Perhaps PARP-1 facilitates, by polymer formation, chromatin opening and therefore better access of DNA-PK to the break, or weak poly(ADP-ribosyl)ation might induce a conformational change in the 3D structure of the kinase, thus increasing its activity. It was shown recently that the activity of another PIKK-member, ATM (ataxia telangiectasia mutated), is positively modulated by PAR (67). Thus, it becomes more and more evident that PARP-1 and PARP2 are general DNA damage sensing and repair regulating factors.

The impact of PARP-1 on genomic stability is exploited in cancer therapy. It was reported that simultaneous treatment of tumours with DNA-damaging agents like temozolomide and PARP inhibitors increases the efficacy of the chemotherapeutic drug (68-70). Inactivated PARP blocks the repair of induced DNA lesions

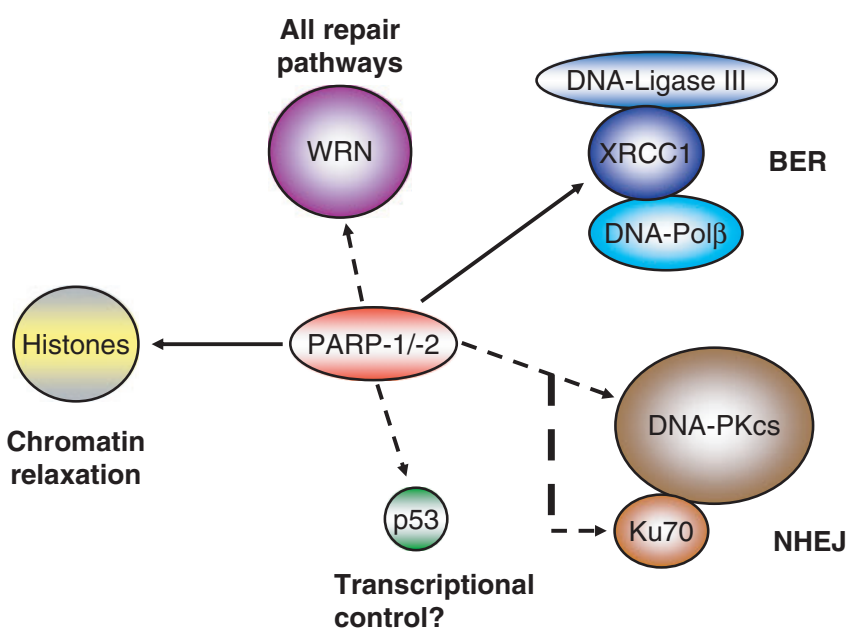

Figure 3. Direct interactions of PARP 1/2 with other proteins important in repair. PARP 1/ 2 and their product PAR interact with several other proteins involved in different repair pathways. Histones are a prominent target of poly(ADP ribosyl)ation, releasing them from DNA. A full line arrow marks interactions shown for both PARPs, whereas dashed arrows indicate established interactions between PARP 1 and other proteins.

and therefore triggers cell death more efficiently (71). Recent experimental data take these findings one step further. Tumour cells with non-functional BRCA-1/-2 proteins can be sensitized to cell death by simple PARP inhibition even in the absence of any additional treatment (72-74). The single-strand breaks that are accumulating in this setting are converted into double-strand breaks by DNA replication. As the BRCA proteins are integral components of the signalling and repair machinery responsive to this kind of lesions, repair by $\mathrm{HR}$ is blocked, so the cells will die as a result of the persistent damage. These findings, however, have been challenged recently (75), and it was suggested that the observed results may have been due to unspecific effects of PARP inhibition.

\section{PARP localizing to specific intracellular compartments}

Seemingly PARPs are not only regulating DNA repair pathways, as they have also been found at chromosomeorganizing regions like the centromere, the telomere or the centrosome. PARP-1 has been shown to localize to the centromere, and centromeric proteins have been shown to be a substrate for covalent poly(ADP-ribosyl)ation (3) but the impact of this modification has been elusive so far.

PARP-2 seems to be specifically involved in X-chromosomal stability, as Parp 2 knockout mice showed a decreased frequency of female pups born (76). Cytogenetic analyses revealed a selectively increased embryonic lethality in females due to X-chromosomal instability.

PARP-1 seems to be involved in maintaining euploidy of mammalian cells as Parpl knockout cells in culture show increased aneuploidy; the same is the case for wild-type cells under chronic treatment with PARP inhibitors (77-79). This effect depends on a deregulation of centrosome duplication, leading to increased 
numbers of spindle-pole bodies and, as a consequence, aberrant mitosis. One hallmark of cancer is aneuploidy. Likewise, fibroblasts from Parpl knockout mice show increased polyploidy, raising the question if PARP-1 is also involved in mitotic checkpoints (77). Also, the product of PARPs, poly(ADP-ribose), has been shown to be an integral component of mitotic spindles, responsible for their stability $(9,10)$.

At chromosomal ends, a protein complex designated as 'shelterin' or 'telosome' forms together with roughly $20 \mathrm{~kb}$ of the repetitive hexanucleotide DNA $\left(\mathrm{T}_{2} \mathrm{AG}_{3}\right)$ a protective cap, the telomere $(80,81)$. Telomeric DNA ends in a single-stranded $3^{\prime}$ extension, which is able to fold back and invade the double-stranded region of the same sequence. This plasmid-like structure is called t-loop and has been detected in vitro as well as in vivo $(82,83)$. Therefore, the normally highly recombinogenic combination of a DNA double-strand break with a single-stranded extension is masked and shielded from the repair machinery to facilitate genomic stability. Two specific proteins bind the telomeric double strand, i.e. telomeric repeat binding factor (TRF) 1 and 2. Whereas TRF-1 is responsible for telomere length regulation by a protein counting mechanism $(84,85)$, TRF-2 stabilizes the t-loop and is therefore indispensable for the functionality of the telomere (85-87). Expression of a dominant-negative version of TRF-2 immediately uncaps telomeres, followed by initiation of repair and subsequently senescence or chromosomal endto-end fusions and massive cell death. Another feature of TRF-2 is its direct inhibition of ATM (ataxia telangiectasia mutated), the key protein kinase in activating DNA double-strand repair $(88)$. On the other hand, the t-loop inhibits progression of the replication fork in vitro (89). Therefore, this secondary structure has to be resolved in concert with cell cycle progression in order to enable complete replication through telomeric DNA. In analogy to TRF-1, where the tankyrases 1 and 2 (PARP-5 subfamily) have been shown to dislodge TRF-1 from DNA by poly(ADP-ribosyl)ation $(13,90,91)$, TRF-2 interacts with PARP-1 $(15,16)$ and in a special case with PARP-2 (14). Displacing TRF-2 from the DNA would result in an 'open-state' telomere without t-loop, not hindering progression of the replication machinery anymore. Thus, timed on and off shuttling of TRF-2 is important for suppressing unscheduled repair (recombination) as well as telomere replication, keeping telomeric functions intact and avoiding induction of a damage signal as discussed above. The WRN protein, a helicase, may aid in the process of resolving the t-loop after TRF-2 release (discussed below).

\section{PARP-1, WRN and p53: three proteins, one mission-genomic stability}

Interaction of PARP and PAR with proteins already known to affect ageing adds an additional layer to the involvement of PARP in this process. The most prominent example is the modulation of the Werner syndrome protein (WRN) activity by PARP-1 but not PARP-2 (92). In mice, double knockout of Parpl and Wrn leads to increased sister-chromatid exchange and an earlier onset of tumorigenesis than in each single knockout (93). Together with BLM (Blooms syndrome), RTD/RecQ4 (Rothmund-Thompson disorder) and other proteins, WRN belongs to the family of RecQ helicases (94). As an exception within this family, WRN also contains an exonuclease activity. Patients with the rare recessive disorder Werner syndrome show accelerated ageing after the onset of puberty with symptoms including cataracts, greying and loss of hair, atherosclerosis, osteoporosis, diabetes mellitus and a higher incidence of sarcomas, melanomas and meningiomas. On the molecular level, Werner syndrome cells show increased numbers of chromosomal translocations and deletions, an extended S-phase due to persistent DNA damage, a higher sensitivity to DNA-damaging agents, accelerated telomere loss and shortened life span in culture. WRN associates with many proteins involved in DNA repair, replication and recombination like proliferating cell nuclear antigen (PCNA), replication protein A (RPA), all three DNA-PK subunits ( $\mathrm{Ku} 70, \mathrm{Ku} 80$ and DNA-PKcs), p53, DNA polymerases $\beta$ and $\delta$ (95), flap-endonuclease 1 (FEN-1) $(96,97)$, telomeric repeat-binding factor 2 (TRF-2) $(98,99)$ and PARP-1 (92). WRN interacts with most of these proteins via its RecQ homology domain. WRN acts in vitro on secondary structures that arise during replication block, DNA repair and at the telomeric t-loop (100). In BER, WRN seems to activate the long patch pathway by direct stimulation of DNA polymerase $\delta$ and the strand displacement synthesis activity of DNA polymerase $\beta$ (95). It also stimulates the activity of FEN-1 leading to more efficient cleavage of the overhanging displaced DNA strand, the 'flap', which is a by-product of the synthesis. The strong interdependence of WRN and PARP-1 is underlined by the fact that cells from WRN patients show a modified pattern of poly(ADP-ribosyl)ated proteins, i.e. less heteromodification of other proteins yet unchanged automodification of PARP-1 (101). Interaction with Ku70/Ku80 stimulates WRN exonuclease activity (102), which may be required to resolve secondary structures or trim blocked substrates in combination with the helicase to facilitate NHEJ. On telomeres, WRN directly binds to TRF-2 and is necessary in telomere regulation, i.e. opening up the t-loop (103). This is supported by the observation that cells from WRN patients display chromosomal fusions and faster telomere shortening, features similar to expression of a dominant-negative version of TRF-2. Besides the direct interaction between PARP-1 and WRN, the two proteins share many binding partners, such as p53, DNA-PK and TRF-2. Both proteins are especially involved in the long-patch pathway of BER. Both have a positive impact on telomere length. In contrast, whereas Ku70/80 stimulates WRN's exonuclease activity, PARP-1 inhibits both WRN functions (Figure 4). This is probably not due to direct modification of WRN protein, although one publication reported WRN as a substrate for poly(ADP-ribosyl)ation. All three functional units (PARP-1, WRN, DNA-PK with $\mathrm{Ku} 70 / 80$ and DNA-PKcs) can form a complex, in which polymer-modified $\mathrm{Ku} 70 / 80$ shows a decreased stimulation of WRN (102). Upon automodification of PARP-1, the inhibition of WRN exonuclease and helicase 


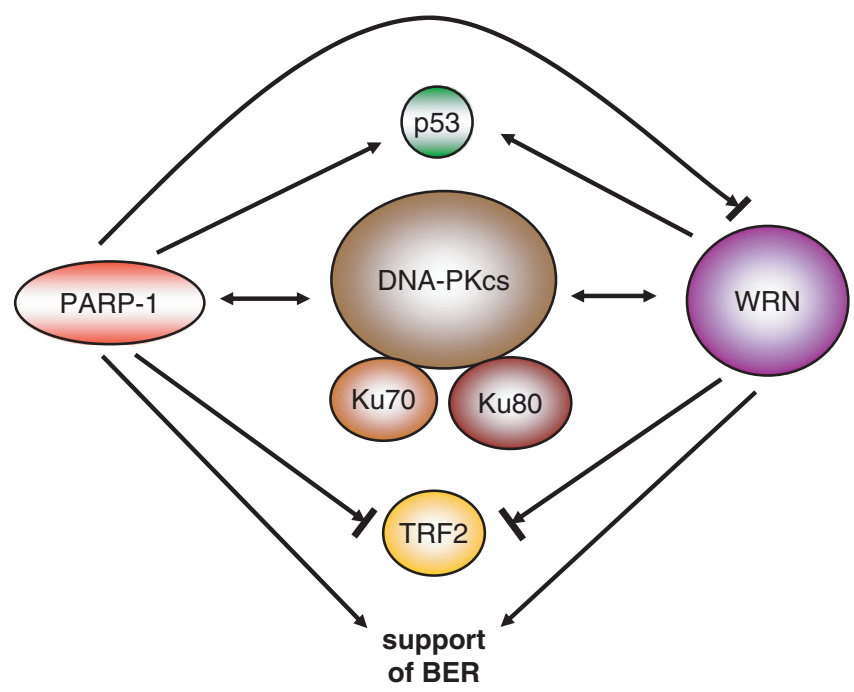

Figure 4. Interaction map between PARP 1 and the Werner syndrome protein WRN. The two proteins share many overlapping interaction pathways. There is a reciprocal interaction with DNA PK (double headed arrow), interaction with $\mathrm{p} 53$, stimulation and/or modulation of base excision repair (BER, one headed arrow), and inhibition of TRF 2 DNA binding (blocked arrow). PARP 1 also inhibits WRN functions if in an unmodified state.

activity is released. Therefore, PARP-1 may regulate the timing of WRN activity towards its substrates, i.e. giving other repair proteins a trial before WRN steps in.

Interaction of $\mathrm{p} 53$, the 'guardian of the genome', with PARP-1 and PAR is complex and not fully understood (104-112). Whereas poly(ADP-ribosyl)ation seems to stabilize $\mathrm{p} 53$, it also inhibits the important transcriptional activity of p53. Moreover, p53 can bind PAR noncovalently at three sites, two of which are located in the DNA-binding domain and one in the C-terminal oligomerization domain. The function of PAR bound to p53 has to be investigated more deeply.

\section{PARP and ageing}

Fifteen years ago, Grube and Bürkle showed that DNA strand break-dependent PARP activity in permeabilized peripheral blood mononuclear cells (PBMC) correlates positively with the maximal life span in mammalian species (113). Human PBMC displayed a 5-fold increase in PAR production compared to rat PBMC, yet expressed the same amount of PARP-1 protein. Subsequent experiments with recombinant PARP-1 proteins from man and rat revealed a 2-fold higher automodification level in human PARP-1 although classical enzymatic parameters like Vmax and $\mathrm{Km}$ were not different (114). The interplay with other proteins either relaying the PAR signal or being directly influenced by it probably enhances evolutionary divergences. Interestingly, both in humans and rats, PARP activity declined with donor age. On the other hand, a study using immortalized lymphocytes proved that PARP activity was higher in cells from centenarians than in appropriate controls (115). Significance was even further increased if activity was normalized not to total protein but to PARP-1 content alone. Thus, a high (but probably tightly controlled) PARP activity may be beneficial for a prolonged life by suppressing genomic instability and tumorigenesis. Therefore, it was obvious to screen for polymorphisms within the human PARP-1 gene locus (Parp1). Although several polymorphisms in Parp1 have been reported, only a minority of them change the amino acids sequence and none of them could be correlated with 'successful' ageing as exemplified by centenarians in a first experimental setting (116). Intriguingly, recent papers report that the V762A polymorphism, originally reported by Cottet and colleagues (116), is indeed associated with diminished PARP-1 activity (117) and increased risk of some but not all types of cancer $(118,119)$. Moreover, a duplication within a PARP1 pseudogene at $13 \mathrm{q} 33$ seems to be a predisposition marker for increased cancer risk (120). Also, a polymorphic tract of CA repeats in the promoter region seems to pre-dispose to rheumatoid arthritis in the Spanish population (121), although it is not clear if this variance influences transcription and/or activity levels. But still, as valid data are missing that integrate successful ageing and molecular mechanisms responsible for higher PARP activity, the factors determining the positive association remain elusive.

\section{SUMMARY}

PARP activity may positively influence 'healthy ageing' through several pathways. The classical view is that this is mediated by facilitating and regulating DNA strand break repair. Also, the role of PARP activity in triggering cell death either by energy depletion or by induction of AIF may protect the individual from the uncontrolled outgrowth of potentially mutated cells after genotoxic insult. PARP-1 and PARP-2, however, not only stabilize the genome by their repair activity, but have also been found at other locations. PARP-1 and PARP-2 were detected at the centromere, and centromeric proteins have been shown to be a substrate for poly(ADP-ribosyl)ation. Additionally, PARP-1 is a part of the centrosome, i.e. the spindle organizer, and pharmacological inhibition of PARP-1 or Parpl knockout leads to increased rates of aneuploidy in cultured cells. Also, it has been shown that PAR is a stabilizing component of the spindle, although its precise function and its origin has not been clarified yet. Last but not least, PARP-1 interacts with the telomere DNA double-strand binding protein TRF-2. TRF-2 is responsible for telomeric stability and suppression of unscheduled activity of the double-strand break repair machinery by maintaining the t-loop; it is a key component of the proteinaceous complex called shelterin/telosome, which integrates telomere length regulation as well as protective activities. On the other hand, the t-loop inhibits passing of the replication fork, and therefore dislodging the proteins holding the t-loop in place is necessary for complete duplication of the genome. As a candidate mechanism, PARP-1 could modify TRF-2 and target it for destruction, counteracting accelerated telomere shortening and accompanied senescence or cell death. In mice, PARP-2 is involved especially in female X-chromosome stability. Independent of 


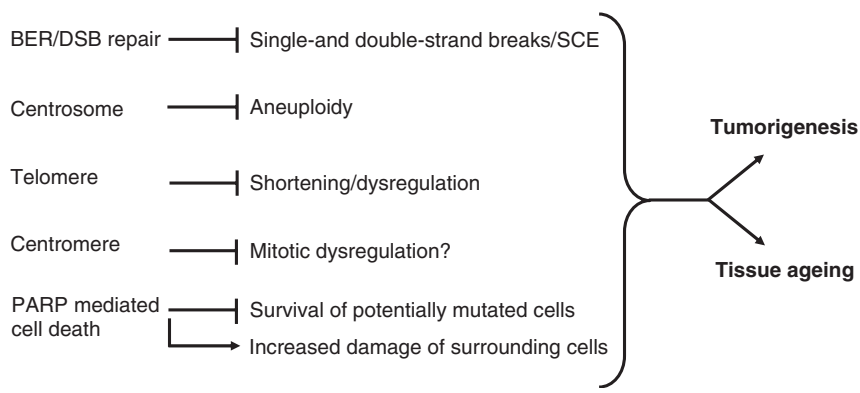

Figure 5. Poly(ADP ribose) as a non proteinaceous tumour suppressor. Poly(ADP ribosyl)ation not only regulates repair pathways as BER and DNA double strand break repair (DNA PK, ATM), but also con tributes to other aspects of maintaining genomic stability by PAR interaction with the centrosome and (heterochromatic) chromosome regions like the telomere and the centromere. Blocked lines describe factors inhibited by PARP activity and arrows stand for positive correlation. The effects in the middle column lead to either cancer initiation or accelerated tissue ageing. Taken together, the cellular poly(ADP ribose) system is an important factor in suppressing tumorigenesis or tissue ageing and is needed for maintaining cellular functionality.

its genome-stabilizing functions, PARP-1 also impacts on transcription. The interaction of PARP-1 with the key regulator of the immune system, $\mathrm{NF \kappa B}$, and the dependence of the latter on the presence of PARP-1 for its activity (at least in the setting of some NFKB-regulated promoters) impacts strongly on the functionality of this important line of defence against deleterious invasion of pathogenic micro-organisms. The importance of an intact PAR-system including PARP-1 and PARP-2 is underlined by the fact that double-knockout mice display embryonic lethality (76). Therefore, discrimination between the partially overlapping functions of PARP-1 and PARP-2 is difficult, and redundancy may mask aspects that are normally accounted for by one of the two proteins in an in vivo setting.

In conclusion, there are two major branches of how PARP activity can influence the organismal ageing process: First, there is modulation of the immune system via interaction with $\mathrm{NF \kappa B}$, which could lead to a better fitness in the constant battle with pathogens our bodies have to fight. Second, there is maintenance of genomic stability, subdivided in several pathways. (i) Regulation of BER (via interaction with XRCC1); (ii) modulating DNA double-strand break repair (DNA-PK, ATM); (iii) telomere stability (TRF-2/shelterin); (iv) spindle organization and stability (centrosome, PAR at mitotic microtubules, $\mathrm{X}$-chromosome) and (v) death of cells with heavily damaged DNA (AIF, energy depletion). All of these factors merge into the suppression of mutations potentially leading to tumorigenesis. But - as the other side of the coin - it also can disturb tissue renewal, leading to reduced functional plasticity of organs. As PARP activity declines with the age of the individual, the regulative interplay may not be effective enough to maintain cellular fitness. The loss of functional cells from tissues either by senescence or cell death will compromise the respective organ functions (Figure 5). Along the same lines, successful ageing of centenarians may be supported by high PARP activity leaving regulatory circuits intact and preventing cancer formation.

\section{ACKNOWLEDGEMENT}

Funding to pay the Open Access publication charges for this article was provided by the Deutsche Forschungsgemeinschaft (International Research Training Group 1331 Konstanz/Zürich, "Cell-based Characterization of Disease Mechanisms in Tissue Destruction and Repair").

Conflict of interest statement. None declared.

\section{REFERENCES}

1. Chambon,P., Weill,J.D. and Mandel,P. (1963) Nicotinamide mononucleotide activation of new DNA dependent polyadenylic acid synthesizing nuclear enzyme. Biochem. Biophys. Res. Commun., 11, 3943 .

2. Earle,E., Saxena,A., MacDonald,A., Hudson,D.F., Shaffer,L.G., Saffery,R., Cancilla,M.R., Cutts,S.M., Howman,E. et al. (2000) Poly(ADP ribose) polymerase at active centromeres and neocen tromeres at metaphase. Hum. Mol. Genet., 9, 187194.

3. Saxena,A., Saffery,R., Wong,L.H., Kalitsis,P. and Choo,K.H. (2002) Centromere proteins Cenpa, Cenpb, and Bub3 interact with poly(ADP ribose) polymerase 1 protein and are poly (ADP ribosyl)ated. J. Biol. Chem., 277, 2692126926.

4. Slattery,E., Dignam,J.D., Matsui,T. and Roeder,R.G. (1983) Purification and analysis of a factor which suppresses nick induced transcription by RNA polymerase II and its identity with poly(ADP ribose) polymerase. J. Biol. Chem., 258, 59555959.

5. Oei,S.L., Griesenbeck,J., Schweiger,M. and Ziegler,M. (1998) Regulation of RNA polymerase II dependent transcription by poly(ADP ribosyl)ation of transcription factors. J. Biol. Chem., 273, 3164431647.

6. Hassa,P.O. and Hottiger,M.O. (1999) A role of poly (ADP ribose) polymerase in NF kappaB transcriptional activation. Biol. Chem., 380, 953959.

7. Hassa,P.O., Buerki,C., Lombardi,C., Imhof,R. and Hottiger,M.O. (2003) Transcriptional coactivation of nuclear factor kappaB dependent gene expression by p300 is regulated by poly(ADP) ribose polymerase 1. J. Biol. Chem., 278, 4514545153.

8. Tulin,A., Stewart,D. and Spradling,A.C. (2002) The Drosophila heterochromatic gene encoding poly(ADP ribose) polymerase (PARP) is required to modulate chromatin structure during development. Genes Dev., 16, 21082119.

9. Chang,P., Jacobson,M.K. and Mitchison,T.J. (2004) Poly(ADP ribose) is required for spindle assembly and structure. Nature, 432, 645649.

10. Chang,P., Coughlin,M. and Mitchison,T.J. (2005) Tankyrase 1 polymerization of poly(ADP ribose) is required for spindle structure and function. Nat. Cell Biol., 7, 11331139.

11. Chang,W., Dynek,J.N. and Smith,S. (2005) NuMA is a major acceptor of poly(ADP ribosyl)ation by tankyrase 1 in mitosis. Biochem. J., 391, 177184.

12. Dynek,J.N. and Smith,S. (2004) Resolution of sister telomere association is required for progression through mitosis. Science, 304, 97100 .

13. Smith,S., Giriat,I., Schmitt,A. and de Lange,T. (1998) Tankyrase, a poly(ADP ribose) polymerase at human telomeres. Science, 282, 14841487.

14. Dantzer,F., Giraud Panis,M.J., Jaco,I., Ame,J.C., Schultz,I., Blasco,M., Koering,C.E., Gilson,E., Menissier de Murcia,J. et al. (2004) Functional interaction between poly(ADP Ribose) polymer ase 2 (PARP 2) and TRF2: PARP activity negatively regulates TRF2. Mol. Cell. Biol., 24, 15951607. 
15. O'Connor,M.S., Safari,A., Liu,D., Qin,J. and Songyang,Z. (2004) The human Rapl protein complex and modulation of telomere length. J. Biol. Chem., 279, 2858528591.

16. Gomez,M., Wu,J., Schreiber,V., Dunlap,J., Dantzer,F., Wang,Y. and Liu,Y. (2006) PARP1 Is a TRF2 associated poly(ADP ribose)polymerase and protects eroded telomeres. Mol. Biol. Cell., 17, 16861696

17. Chi,N.W. and Lodish,H.F. (2000) Tankyrase is a golgi associated mitogen activated protein kinase substrate that interacts with IRAP in GLUT4 vesicles. J. Biol. Chem., 275, 3843738444.

18. Yeh,T.Y., Sbodio,J.I., Tsun,Z.Y., Luo,B. and Chi,N.W. (2006) Insulin stimulated exocytosis of GLUT4 is enhanced by IRAP and its partner tankyrase. Biochem. $J$.

19. Yeh,T.Y., Meyer,T.N., Schwesinger,C., Tsun,Z.Y., Lee,R.M. and Chi,N.W. (2006) Tankyrase recruitment to the lateral membrane in polarized epithelial cells: regulation by cell cell contact and protein poly(ADP ribosyl)ation. Biochem. J., 399, 415425.

20. Kickhoefer,V.A., Siva,A.C., Kedersha,N.L., Inman,E.M., Ruland,C., Streuli,M. and Rome,L.H. (1999) The 193 kD vault protein, VPARP, is a novel poly(ADP ribose) polymerase. J. Cell Biol., 146, 917928.

21. Berger,N.A., Sims,J.L., Catino,D.M. and Berger,S.J. (1983) Poly(ADP ribose) polymerase mediates the suicide response to massive DNA damage: studies in normal and DNA repair defective cells. Princess Takamatsu Symp., 13, 219226.

22. Yu,S.W., Wang,H., Poitras,M.F., Coombs,C., Bowers,W.J., Federoff,H.J., Poirier,G.G., Dawson,T.M. and Dawson,V.L. (2002) Mediation of poly(ADP ribose) polymerase 1 dependent cell death by apoptosis inducing factor. Science, 297, 259263.

23. Burkle,A. (2005) Poly(ADP ribose). The most elaborate metabolite of NAD + . FEBS J., 272, 45764589

24. Burkle,A. (2006) DNA repair and PARP in aging. Free Radic. Res., 40, 12951302

25. Burkle,A. (2001) Poly(APD ribosyl)ation, a DNA damage driven protein modification and regulator of genomic instability. Cancer Lett., 163, 15 .

26. Shieh,W.M., Ame,J.C., Wilson,M.V., Wang,Z.Q., Koh,D.W., Jacobson,M.K. and Jacobson,E.L. (1998) Poly(ADP ribose) poly merase null mouse cells synthesize ADP ribose polymers. J. Biol. Chem., 273, 3006930072.

27. Ha,H.C. and Snyder,S.H. (1999) Poly(ADP ribose) polymerase is a mediator of necrotic cell death by ATP depletion. Proc. Natl Acad. Sci. USA, 96, 1397813982

28. Kupper,J.H., Muller,M., Jacobson,M.K., Tatsumi Miyajima,J., Coyle,D.L., Jacobson,E.L. and Burkle,A. (1995) trans dominant inhibition of poly(ADP ribosyl)ation sensitizes cells against gamma irradiation and N methyl N' nitro N nitrosoguanidine but does not limit DNA replication of a polyomavirus replicon. Mol. Cell. Biol., 15, 31543163 .

29. Schreiber,V., Hunting,D., Trucco,C., Gowans,B., Grunwald,D., De Murcia,G. and De Murcia,J.M. (1995) A dominant negative mutant of human poly(ADP ribose) polymerase affects cell recovery, apoptosis, and sister chromatid exchange following DNA damage. Proc. Natl Acad. Sci. USA, 92, 47534757.

30. Shah,G.M., Poirier,D., Desnoyers,S., Saint Martin,S., Hoflack,J.C., Rong,P., ApSimon,M., Kirkland,J.B. and Poirier,G.G. (1996) Complete inhibition of poly(ADP ribose) polymerase activity prevents the recovery of $\mathrm{C} 3 \mathrm{H} 10 \mathrm{~T} 1 / 2$ cells from oxidative stress. Biochim. Biophys. Acta, 1312, 17.

31. Van Gool,L., Meyer,R., Tobiasch,E., Cziepluch,C., Jauniaux,J.C., Mincheva,A., Lichter,P., Poirier,G.G., Burkle,A. et al. (1997) Overexpression of human poly(ADP ribose) polymerase in trans fected hamster cells leads to increased poly(ADP ribosyl)ation and cellular sensitization to gamma irradiation. Eur. J. Biochem., 244, 1520.

32. Meyer,R., Muller,M., Beneke,S., Kupper,J.H. and Burkle,A. (2000) Negative regulation of alkylation induced sister chromatid exchange by poly(ADP ribose) polymerase 1 activity. Int. J. Cancer, $\mathbf{8 8}$, 351355.

33. Yu,S.W., Andrabi,S.A., Wang,H., Kim,N.S., Poirier,G.G., Dawson,T.M. and Dawson,V.L. (2006) Apoptosis inducing factor mediates poly(ADP ribose) (PAR) polymer induced cell death. Proc. Natl Acad. Sci. USA, 103, 1831418319.
34. Andrabi,S.A., Kim,N.S., Yu,S.W., Wang,H., Koh,D.W., Sasaki,M., Klaus,J.A., Otsuka,T., Zhang,Z. et al. (2006) Poly(ADP ribose) (PAR) polymer is a death signal. Proc. Natl Acad. Sci. USA, 103, 1830818313.

35. Cregan,S.P., Dawson,V.L. and Slack,R.S. (2004) Role of AIF in caspase dependent and caspase independent cell death. Oncogene, 23, 27852796

36. Kaufmann,S.H., Desnoyers,S., Ottaviano,Y., Davidson,N.E. and Poirier,G.G. (1993) Specific proteolytic cleavage of poly(ADP ribose) polymerase: an early marker of chemotherapy induced apoptosis. Cancer Res., 53, 39763985.

37. Negri,C., Donzelli,M., Bernardi,R., Rossi,L., Burkle,A. and Scovassi,A.I. (1997) Multiparametric staining to identify apoptotic human cells. Exp. Cell Res., 234, 174177.

38. Yang,Z., Zingarelli,B. and Szabo,C. (2000) Effect of genetic disruption of poly (ADP ribose) synthetase on delayed production of inflammatory mediators and delayed necrosis during myocardial ischemia reperfusion injury. Shock, 13, 6066.

39. Virag,L. and Szabo,C. (2002) The therapeutic potential of poly(ADP ribose) polymerase inhibitors. Pharmacol. Rev., 54, 375429.

40. Oei,S.L., Griesenbeck,J., Schweiger,M., Babich,V., Kropotov,A and Tomilin,N. (1997) Interaction of the transcription factor YY1 with human poly(ADP ribosyl) transferase. Biochem. Biophys. Res. Commun., 240, 108111

41. Hassa,P.O. and Hottiger,M.O. (2002) The functional role of poly(ADP ribose)polymerase 1 as novel coactivator of NF kappaB in inflammatory disorders. Cell. Mol. Life Sci., 59, 15341553.

42. Oliver,F.J., Menissier de Murcia,J., Nacci,C., Decker,P Andriantsitohaina,R., Muller,S., de la Rubia,G., Stoclet,J.C. and de Murcia,G. (1999) Resistance to endotoxic shock as a consequence of defective NF kappaB activation in poly (ADP ribose) polymer ase 1 deficient mice. EMBO J., 18, 44464454.

43. Hasko,G., Mabley,J.G., Nemeth,Z.H., Pacher,P., Deitch,E.A. and Szabo,C. (2002) Poly(ADP ribose) polymerase is a regulator of chemokine production: relevance for the pathogenesis of shock and inflammation. Mol. Med., 8, 283289.

44. Liaudet,L., Szabo,A., Soriano,F.G., Zingarelli,B., Szabo,C. and Salzman,A.L. (2000) Poly (ADP ribose) synthetase mediates intest inal mucosal barrier dysfunction after mesenteric ischemia. Shock, 14, 134141

45. Jijon,H.B., Churchill,T., Malfair,D., Wessler,A., Jewell,L.D., Parsons,H.G. and Madsen,K.L. (2000) Inhibition of poly(ADP ribose) polymerase attenuates inflammation in a model of chronic colitis. Am. J. Physiol. Gastrointest. Liver Physiol., 279, G641 G651.

46. Mandir,A.S., Przedborski,S., Jackson Lewis,V., Wang,Z.Q., Simbulan Rosenthal,C.M., Smulson,M.E., Hoffman,B.E., Guastella,D.B., Dawson,V.L. et al. (1999) Poly(ADP ribose) poly merase activation mediates 1 methyl 4 phenyl 1, 2,3,6 tetrahydro pyridine (MPTP) induced parkinsonism. Proc. Natl Acad. Sci. USA, 96, 57745779

47. Eliasson,M.J., Sampei,K., Mandir,A.S., Hurn,P.D. Traystman,R.J., Bao,J., Pieper,A., Wang,Z.Q., Dawson,T.M. et al. (1997) Poly(ADP ribose) polymerase gene disruption renders mice resistant to cerebral ischemia. Nat. Med., 3, 10891095.

48. Pieper,A.A., Walles,T., Wei,G., Clements,E.E., Verma,A., Snyder,S.H. and Zweier,J.L. (2000) Myocardial postischemic injury is reduced by polyADPripose polymerase 1 gene disruption. Mol. Med., 6, 271282.

49. Mota Filipe,H., Sepodes,B., McDonald,M.C., Cuzzocrea,S., Pinto,R. and Thiemermann,C. (2002) The novel PARP inhibitor 5 aminoisoquinolinone reduces the liver injury caused by ischemia and reperfusion in the rat. Med. Sci. Monit., 8, BR444 BR453.

50. Fiorillo,C., Ponziani,V., Giannini,L., Cecchi,C., Celli,A., Nediani,C., Perna,A.M., Liguori,P., Nassi,N. et al. (2003) Beneficial effects of poly (ADP ribose) polymerase inhibition against the reperfusion injury in heart transplantation. Free Radic. Res., 37, 331339.

51. Szabo,C. (2002) PARP as a drug target for the therapy of diabetic cardiovascular dysfunction. Drug News Perspect., 15 197205.

52. Szabo,C., Zanchi,A., Komjati,K., Pacher,P., Krolewski,A.S., Quist,W.C., LoGerfo,F.W., Horton,E.S. and Veves,A. (2002) Poly(ADP Ribose) polymerase is activated in subjects at risk of 
developing type 2 diabetes and is associated with impaired vascular reactivity. Circulation, 106, 26802686.

53. Beneke,S. and Burkle,A. (2004) Poly(ADP ribosyl)ation, PARP, and aging. Sci. Aging Knowledge Environ., 2004, re9.

54. Wilson,S.H. and Kunkel,T.A. (2000) Passing the baton in base excision repair. Nat. Struct. Biol., 7, 176178.

55. Mitra,S., Boldogh,I., Izumi,T. and Hazra,T.K. (2001) Complexities of the DNA base excision repair pathway for repair of oxidative DNA damage. Environ. Mol. Mutagen., 38, 180190.

56. Dantzer,F., Schreiber,V., Niedergang,C., Trucco,C., Flatter,E., De La Rubia,G., Oliver,J., Rolli,V., Menissier de Murcia,J. et al. (1999) Involvement of poly(ADP ribose) polymerase in base excision repair. Biochimie, 81, 6975.

57. Dantzer,F., de La Rubia,G., Menissier De Murcia,J., Hostomsky,Z., de Murcia,G. and Schreiber,V. (2000) Base excision repair is impaired in mammalian cells lacking Poly(ADP ribose) polymerase 1. Biochemistry, 39, 75597569.

58. Schreiber,V., Ame,J.C., Dolle,P., Schultz,I., Rinaldi,B., Fraulob,V., Menissier de Murcia,J. and de Murcia,G. (2002) Poly(ADP ribose) polymerase 2 (PARP 2) is required for efficient base excision DNA repair in association with PARP 1 and XRCC1. J. Biol. Chem., 277, 2302823036

59. Prasad,R., Lavrik,O.I., Kim,S.J., Kedar,P., Yang,X.P., Vande Berg,B.J. and Wilson,S.H. (2001) DNA polymerase beta mediated long patch base excision repair. Poly(ADP ribose)polymerase 1 stimulates strand displacement DNA synthesis. J. Biol. Chem., 276, 3241132414

60. Masson,M., Niedergang,C., Schreiber,V., Muller,S., Menissier de Murcia,J. and de Murcia,G. (1998) XRCC1 is specifically associated with poly(ADP ribose) polymerase and negatively regulates its activity following DNA damage. Mol. Cell. Biol., 18, 35633571

61. El Khamisy,S.F., Masutani,M., Suzuki,H. and Caldecott,K.W. (2003) A requirement for PARP 1 for the assembly or stability of XRCC1 nuclear foci at sites of oxidative DNA damage. Nucleic Acids Res., 31, 55265533.

62. Leppard,J.B., Dong,Z., Mackey,Z.B. and Tomkinson,A.E. (2003) Physical and functional interaction between DNA ligase IIIalpha and poly(ADP Ribose) polymerase 1 in DNA single strand break repair. Mol. Cell. Biol., 23, 59195927.

63. Kaina,B. (2003) DNA damage triggered apoptosis: critical role of DNA repair, double strand breaks, cell proliferation and signaling. Biochem. Pharmacol., 66, 15471554.

64. Ruscetti,T., Lehnert,B.E., Halbrook,J., Le Trong,H., Hoekstra,M.F., Chen,D.J. and Peterson,S.R. (1998) Stimulation of the DNA dependent protein kinase by poly(ADP ribose) polymer ase. J. Biol. Chem., 273, 1446114467.

65. Pleschke,J.M., Kleczkowska,H.E., Strohm,M. and Althaus,F.R (2000) Poly(ADP ribose) binds to specific domains in DNA damage checkpoint proteins. J. Biol. Chem., 275, 4097440980.

66. Malanga,M. and Althaus,F.R. (2005) The role of poly(ADP ribose) in the DNA damage signaling network. Biochem. Cell Biol., 83, 354364.

67. Haince,J.F., Kozlov,S., Dawson,V.L., Dawson,T.M., Hendzel,M.J., Lavin,M.F. and Poirier,G.G. (2007) Ataxia telangiectasia mutated (ATM) signaling network is modulated by a novel poly(ADP ribose) dependent pathway in the early response to DNA damaging agents. J. Biol. Chem., 282, 1644116453.

68. Boulton,S., Pemberton,L.C., Porteous,J.K., Curtin,N.J., Griffin,R.J., Golding,B.T. and Durkacz,B.W. (1995) Potentiation of temozolomide induced cytotoxicity: a comparative study of the biological effects of poly(ADP ribose) polymerase inhibitors. $B r . J$ Cancer, 72, 849856.

69. Tentori,L., Leonetti,C., Scarsella,M., d'Amati,G., Portarena,I., Zupi,G., Bonmassar,E. and Graziani,G. (2002) Combined treatment with temozolomide and poly(ADP ribose) polymerase inhibitor enhances survival of mice bearing hematologic malignancy at the central nervous system site. Blood, 99, 22412244.

70. Calabrese,C.R., Almassy,R., Barton,S., Batey,M.A., Calvert,A.H., Canan Koch,S., Durkacz,B.W., Hostomsky,Z., Kumpf,R.A. et al. (2004) Anticancer chemosensitization and radiosensitization by the novel poly(ADP ribose) polymerase 1 inhibitor AG14361. J. Natl Cancer Inst., 96, 5667
71. Beneke,S., Diefenbach,J. and Burkle,A. (2004) Poly(ADP ribosy 1)ation inhibitors: promising drug candidates for a wide variety of pathophysiologic conditions. Int. J. Cancer, 111, 813818.

72. Bryant,H.E., Schultz,N., Thomas,H.D., Parker,K.M., Flower,D., Lopez,E., Kyle,S., Meuth,M., Curtin,N.J. et al. (2005) Specific killing of BRCA2 deficient tumours with inhibitors of poly(ADP ribose) polymerase. Nature, 434, 913917.

73. Farmer,H., McCabe,N., Lord,C.J., Tutt,A.N., Johnson,D.A., Richardson,T.B., Santarosa,M., Dillon,K.J., Hickson,I. et al. (2005) Targeting the DNA repair defect in BRCA mutant cells as a therapeutic strategy. Nature, 434, 917921.

74. McCabe,N., Turner,N.C., Lord,C.J., Kluzek,K., Bialkowska,A., Swift,S., Giavara,S., O'Connor,M.J., Tutt,A.N. et al. (2006) Deficiency in the repair of DNA damage by homologous recombination and sensitivity to Poly(ADP Ribose) polymerase inhibition. Cancer Res., 66, 81098115 .

75. De Soto,J.A., Wang,X., Tominaga,Y., Wang,R.H., Cao,L., Qiao,W., Li,C., Xu,X., Skoumbourdis,A.P. et al. (2006) The inhibition and treatment of breast cancer with poly (ADP ribose) polymerase (PARP 1) inhibitors. Int. J. Biol. Sci., 2, 179185.

76. Menissier de Murcia,J., Ricoul,M., Tartier,L., Niedergang,C., Huber,A., Dantzer,F., Schreiber,V., Ame,J.C., Dierich,A. et al. (2003) Functional interaction between PARP 1 and PARP 2 in chromosome stability and embryonic development in mouse. EMBO J., 22, 22552263

77. Simbulan Rosenthal,C.M., Haddad,B.R., Rosenthal,D.S., Weaver,Z., Coleman,A., Luo,R., Young,H.M., Wang,Z.Q., Ried,T. et al. (1999) Chromosomal aberrations in $\operatorname{PARP}(/)$ mice: genome stabilization in immortalized cells by reintroduction of poly(ADP ribose) polymerase cDNA. Proc. Natl Acad. Sci. USA, 96, 1319113196.

78. Kanai,M., Uchida,M., Hanai,S., Uematsu,N., Uchida,K. and Miwa,M. (2000) Poly(ADP ribose) polymerase localizes to the centrosomes and chromosomes. Biochem. Biophys. Res. Commun., 278, 385389 .

79. Kanai,M., Tong,W.M., Sugihara,E., Wang,Z.Q., Fukasawa,K. and Miwa,M. (2003) Involvement of poly(ADP Ribose) polymerase 1 and poly(ADP Ribosyl)ation in regulation of centrosome function. Mol. Cell. Biol., 23, 24512462.

80. de Lange,T. (2005) Shelterin: the protein complex that shapes and safeguards human telomeres. Genes Dev., 19, 21002110.

81. Liu,D., O'Connor,M.S., Qin,J. and Songyang,Z. (2004) Telosome, a mammalian telomere associated complex formed by multiple telomeric proteins. J. Biol. Chem., 279, 5133851342.

82. Griffith J.D., Comeau,L., Rosenfield,S., Stansel,R.M., Bianchi,A., Moss,H. and de Lange,T. (1999) Mammalian telomeres end in a large duplex loop. Cell, 97, 503514

83. Nikitina,T. and Woodcock,C.L. (2004) Closed chromatin loops at the ends of chromosomes. J. Cell Biol., 166, 161165.

84. Bianchi,A., Smith,S., Chong,L., Elias,P. and de Lange,T. (1997) TRF1 is a dimer and bends telomeric DNA. EMBO J., 16, 17851794.

85. Smogorzewska,A., van Steensel,B., Bianchi,A., Oelmann,S., Schaefer,M.R., Schnapp,G. and de Lange,T. (2000) Control of human telomere length by TRF1 and TRF2. Mol. Cell. Biol., 20, 16591668

86. van Steensel,B., Smogorzewska,A. and de Lange,T. (1998) TRF2 protects human telomeres from end to end fusions. Cell, 92, 401413.

87. Karlseder,J., Broccoli,D., Dai,Y., Hardy,S. and de Lange,T. (1999) p53 and ATM dependent apoptosis induced by telomeres lacking TRF2. Science, 283, 13211325.

88. Karlseder,J., Hoke,K., Mirzoeva,O.K., Bakkenist,C., Kastan,M.B., Petrini,J.H. and de Lange,T. (2004) The telomeric protein TRF2 binds the ATM kinase and can inhibit the ATM dependent DNA damage response. PLoS Biol., 2, E240.

89. Ohki,R. and Ishikawa,F. (2004) Telomere bound TRF1 and TRF2 stall the replication fork at telomeric repeats. Nucleic Acids Res., 32 , 16271637.

90. Cook,B.D., Dynek,J.N., Chang,W., Shostak,G. and Smith,S. (2002) Role for the related poly(ADP Ribose) polymerases tankyrase 1 and 2 at human telomeres. Mol. Cell. Biol., 22, 332342. 
91. Chang,W., Dynek,J.N. and Smith,S. (2003) TRF1 is degraded by ubiquitin mediated proteolysis after release from telomeres. Genes Dev., 17, 13281333.

92. von Kobbe,C., Harrigan,J.A., Schreiber,V., Stiegler,P., Piotrowski,J., Dawut,L. and Bohr,V.A. (2004) Poly(ADP ribose) polymerase 1 regulates both the exonuclease and helicase activities of the Werner syndrome protein. Nucleic Acids Res., 32, 40034014.

93. Lebel,M., Lavoie,J., Gaudreault,I., Bronsard,M. and Drouin,R. (2003) Genetic cooperation between the Werner syndrome protein and poly(ADP ribose) polymerase 1 in preventing chromatid breaks, complex chromosomal rearrangements, and cancer in mice. Am. J. Pathol., 162, 15591569.

94. Sharma,S., Doherty,K.M. and Brosh,R.M. Jr (2006) Mechanisms of RecQ helicases in pathways of DNA metabolism and maintenance of genomic stability. Biochem. J., 398, 319337.

95. Harrigan,J.A., Opresko,P.L., von Kobbe,C., Kedar,P.S., Prasad,R., Wilson,S.H. and Bohr,V.A. (2003) The Werner syndrome protein stimulates DNA polymerase beta strand displacement synthesis via its helicase activity. J. Biol. Chem., 278, 2268622695

96. Brosh,R.M. Jr, von Kobbe,C., Sommers,J.A., Karmakar,P., Opresko,P.L., Piotrowski,J., Dianova,I., Dianov,G.L. and Bohr,V.A. (2001) Werner syndrome protein interacts with human flap endonuclease 1 and stimulates its cleavage activity. EMBO J., 20, 57915801.

97. Brosh,R.M. Jr, Driscoll,H.C., Dianov,G.L. and Sommers,J.A (2002) Biochemical characterization of the WRN FEN 1 func tional interaction. Biochemistry, 41, 1220412216.

98. Opresko,P.L., von Kobbe,C., Laine,J.P., Harrigan,J., Hickson,I.D. and Bohr,V.A. (2002) Telomere binding protein TRF2 binds to and stimulates the Werner and Bloom syndrome helicases. J. Biol. Chem., 277, 4111041119.

99. Machwe,A., Xiao,L. and Orren,D.K. (2004) TRF2 recruits the Werner syndrome (WRN) exonuclease for processing of telomeric DNA. Oncogene, 23, 149156.

100. Sharma,S., Otterlei,M., Sommers,J.A., Driscoll,H.C., Dianov,G.L., Kao,H.I., Bambara,R.A. and Brosh,R.M. Jr (2004) WRN helicase and FEN 1 form a complex upon replication arrest and together process branchmigrating DNA structures associated with the replication fork. Mol. Biol. Cell, 15, 734750.

101. von Kobbe,C., Harrigan,J.A., May,A., Opresko,P.L., Dawut,L., Cheng,W.H. and Bohr,V.A. (2003) Central role for the Werner syndrome protein/poly(ADP ribose) polymerase 1 complex in the poly(ADP ribosyl)ation pathway after DNA damage. Mol. Cell. Biol., 23, 86018613.

102. Li,B., Navarro,S., Kasahara,N. and Comai,L. (2004) Identification and biochemical characterization of a Werner's syndrome protein complex with $\mathrm{Ku} 70 / 80$ and poly(ADP ribose) polymerase 1. J. Biol. Chem., 279, 1365913667.

103. Opresko,P.L., Otterlei,M., Graakjaer,J., Bruheim,P., Dawut,L., Kolvraa,S., May,A., Seidman,M.M. and Bohr,V.A. (2004) The Werner syndrome helicase and exonuclease cooperate to resolve telomeric D loops in a manner regulated by TRF1 and TRF2. Mol. Cell, 14, 763774

104. Kumari,S.R., Mendoza Alvarez,H. and Alvarez Gonzalez,R. (1998) Functional interactions of p53 with poly(ADP ribose) polymerase (PARP) during apoptosis following DNA damage: covalent poly(ADP ribosyl)ation of $\mathrm{p} 53$ by exogenous PARP and noncovalent binding of p53 to the $\mathrm{M}(\mathrm{r}) 85,000$ proteolytic fragment. Cancer Res., 58, 50755078.

105. Malanga,M., Pleschke,J.M., Kleczkowska,H.E. and Althaus,F.R. (1998) Poly(ADP ribose) binds to specific domains of p53 and alters its DNA binding functions. J. Biol. Chem., 273, 1183911843
106. Simbulan Rosenthal,C.M., Rosenthal,D.S., Luo,R. and Smulson,M.E. (1999) Poly(ADP ribosyl)ation of p53 during apoptosis in human osteosarcoma cells. Cancer Res., 59, 21902194.

107. Mendoza Alvarez,H. and Alvarez Gonzalez,R. (2001) Regulation of $\mathrm{p} 53$ sequence specific DNA binding by covalent poly(ADP ribosyl)ation. J. Biol. Chem., 276, 3642536430.

108. Simbulan Rosenthal,C.M., Rosenthal,D.S., Luo,R.B., Samara,R., Jung,M., Dritschilo,A., Spoonde,A. and Smulson,M.E. (2001) Poly(ADP ribosyl)ation of $\mathrm{p} 53$ in vitro and in vivo modulates binding to its DNA consensus sequence. Neoplasia, $\mathbf{3}$, 179188

109. Wesierska Gadek,J. and Schmid,G. (2001) Poly(ADP ribose) polymerase 1 regulates the stability of the wild type $\mathrm{p} 53$ protein. Cell. Mol. Biol. Lett., 6, 117140

110. Wesierska Gadek,J., Wojciechowski,J. and Schmid,G. (2003) Central and carboxy terminal regions of human p53 protein are essential for interaction and complex formation with PARP 1. J. Cell. Biochem., 89, 220232.

111. Wesierska Gadek,J., Wojciechowski,J. and Schmid,G. (2003) Phosphorylation regulates the interaction and complex formation between wt p53 protein and PARP 1. J. Cell. Biochem., 89, 12601284.

112. Wieler,S., Gagne,J.P., Vaziri,H., Poirier,G.G. and Benchimol,S. (2003) Poly(ADP ribose) polymerase 1 is a positive regulator of the p53 mediated G1 arrest response following ionizing radiation. J. Biol. Chem., 278, 1891418921.

113. Grube,K. and Burkle,A. (1992) Poly(ADP ribose) polymerase activity in mononuclear leukocytes of 13 mammalian species correlates with species specific life span. Proc. Natl Acad. Sci. USA, 89, 1175911763.

114. Beneke,S., Alvarez Gonzalez,R. and Burkle,A. (2000) Comparative characterisation of poly(ADP ribose) polymerase 1 from two mammalian species with different life span. Exp. Gerontol., 35, 9891002.

115. Muiras,M.L., Muller,M., Schachter,F. and Burkle,A. (1998) Increased poly(ADP ribose) polymerase activity in lymphoblastoid cell lines from centenarians. J. Mol. Med., 76, 346354 .

116. Cottet,F., Blanche,H., Verasdonck,P., Le Gall,I., Schachter,F., Burkle,A. and Muiras,M.L. (2000) New polymorphisms in the human poly(ADP ribose) polymerase 1 coding sequence: lack of association with longevity or with increased cellular poly(ADP ribosyl)ation capacity. J. Mol. Med., 78, 431440.

117. Wang,X.G., Wang,Z.Q., Tong,W.M. and Shen,Y. (2007) PARP1 Val762Ala polymorphism reduces enzymatic activity. Biochem. Biophys. Res. Commun., 354, 122126.

118. Zhang,X., Miao,X., Liang,G., Hao,B., Wang,Y., Tan,W., Li,Y., Guo,Y., He,F. et al. (2005) Polymorphisms in DNA base excision repair genes ADPRT and XRCC1 and risk of lung cancer. Cancer Res., 65, 722726.

119. Zhai,X., Liu,J., Hu,Z., Wang,S., Qing,J., Wang,X., Jin,G., Gao,J. and Shen,H. (2006) Polymorphisms of ADPRT Val762Ala and XRCC1 Arg399Glu and risk of breast cancer in Chinese women: a case control analysis. Oncol. Rep., 15, 247252.

120. Lyn,D., Cherney,B.W., Lalande,M., Berenson,J.R., Lichtenstein,A., Lupold,S., Bhatia,K.G. and Smulson,M. (1993) A duplicated region is responsible for the poly(ADP ribose) polymerase polymorphism, on chromosome 13, associated with a predisposition to cancer. Am. J. Hum. Genet., 52 124134

121. Pascual,M., Lopez Nevot,M.A., Caliz,R., Ferrer,M.A., Balsa,A., Pascual Salcedo,D. and Martin,J. (2003) A poly(ADP ribose) polymerase haplotype spanning the promoter region confers susceptibility to rheumatoid arthritis. Arthritis Rheum., 48, 638641 